\title{
LEÓN FELIPE A LA LUZ DE SU HISTORIA: LA REIVINDICACIÓN RECAPITULADORA Y AUTOBIOGRÁFICA EN EL POEMA "I" DE ROCINANTE
}

\author{
Jorge Chen Sham
}

\begin{abstract}
RESUMEN
La producción lírica de León Felipe responde a la pregunta básica que propone el principio délfico "conócete a ti mismo", el cual cobra nueva dimensión en el poema "I" de Rocinante, pues su condición de poeta se revalora en un diálogo abierto y emotivo con un personaje de ficción que, a sus ojos, tiene existencia propia y se humaniza.
\end{abstract}

\begin{abstract}
León Felipe's lyric production responds to the basic question proposed by the delphic principle, "to know yourself", which takes a new dimension in Rocinante's "I" poem. With this work, his condition of poet is revaluated in an open and emotive dialogue with a fiction character that exists in his own eyes, and becomes human.
\end{abstract}

Con el poemario Ganarás la luz, publicado en 1943, León Felipe empieza la indagación de su biografía personal en términos de una experiencia poética que lo obliga a recorrer incesante y oblicuamente su vida, de manera que en el acto de escritura funde el poeta toda distancia y neutraliza cualquier divergencia en un solo hombre, integrado así a partir de un punto de vista estético y creativo (Bajtín 1982: 133). La construcción y ordenación valorativas, premisa de base de toda práctica autobiográfica según Jean Starobinski (1974: 67), pueden ser resumidas en el subtítulo que el propio León Felipe escoge y que ofrece el título también al primer poema del libro; éste es "Biografía, Poesía y Destino". Con ello, León Felipe no solo nos proporciona un criterio de unidad ideológica para el poemario sino también las claves de su interpretación. Si la comunicación lírica es ante todo una indagación solitaria, íntima y reflexiva del yo, comunicación integradora e indagatoria de un sujeto que se percibe en su relación con los otros y consigo mismo, “(...) todo el proceso lírico desarrollado tiende a terminar con estas preguntas que contienen una decisión, la decisión de adoptar una determinada forma de vida en vista de las inquietudes de la existencia" (Kayser 1981: 452). Así, dentro de la producción felipiana, Ganarás la luz se transforma en el poemario autobiográfico por excelencia, inaugurando una producción poética que, siguiendo el principio délfico del "Gnothi Sauton" (Conócete a ti mismo), responde a la primera pregunta base del pensamiento filosófico occidental: “¿Quién soy yo?".

Esta búsqueda del sujeto mediante la escritura lírica se transforma en una empresa poética en su sentido más prístino, por lo que el sujeto puede integrar esa necesidad imperiosa de 
preocuparse de sí que provoca la asunción del mandato délfico y la vocación a la poesía. Dicho de otra manera, el destino del poeta en tanto hombre, se forja y se crea a la luz de ese proceso recapitulador (Starobinski 1974: 72) que, bajo la forma de misterium tremendum, anima la poesía y la meditación filosófico-lírica. La poesía de León Felipe desarrolla entonces la gran lección de amor intellectualis según la máxima que José Ortega y Gasset expone en Meditaciones del Quijote (de 1914): únicamente el deseo por comprender las cosas permite el conocimiento y este deseo desencadena en el sujeto las ansias de actuar y salvar su circunstancia: "Hemos de buscar a nuestra circunstancia, tal y como ella es, precisamente en lo que tiene de limitación, de peculiaridad, el lugar acertado en la inmensa perspectiva del mundo (...) En suma: la reabsorción de la circunstancia es el destino concreto del hombre" (1990: 75).

Por eso, no nos extrañe que veinte años después, en el poemario Rocinante, empezado en 1965 pero publicado póstumamente (México D.F. 1968), el itinerario propuesto por el subtítulo de Ganarás la luz tenga la misma actualidad y repercusión en la producción de León Felipe. Lo inédito de este poemario radica en esa total integración entre la poesía y la vida como ya se prefiguraba en aquel poemario. La interłogante ¿quién soy yo? cobra ahora nueva dimensión, pues su condición de poeta se revalora en un diálogo abierto y emotivo con un personaje de ficción que, a sus ojos, tiene existencia propia y se humaniza; éste es Rocinante, personaje del Quijote. Así, la literatura, en este espacio de la lírica, emerge como símbolo que puede transformar la vida; lo mismo piensa Unamuno cuando articula su teoría sobre el quijotismo, el cual irradia sus luces y expande su "poderosa vitalidad" (Unamuno 1966: 1231) para todo el que quiera aceptar la verdadera enseñanza del texto cervantino.

En este sentido, la Literatura emerge como símbolo que transforma la vida, ya que la aparición de la figura de Rocinante sirve como engarce a un universo poético al que esclarece e irradia su luz: la biografía y el destino del poeta. En este diálogo que se entabla con Rocinante, el hablante lírico alcanza, gracias a su aspiración eufórica a la completud, una perspectiva recapituladora y valorativa que devela el sentido del hombre y del poeta dentro del cosmos. Desde este punto de vista, es interesante que se asuman en esta comparación no tanto personajes como don Quijote o Sancho Panza sino la figura marginal y de segundo plano de Rocinante, aunque en trabajos anteriores como Versos y oraciones del caminante (1920) o El payaso de las bofetadas y el pescador de caña (1938), pondere con significativo valor la filosofía que enarbola don Quijote en tanto manifestación de una ética ante la vida; tal concepción la encontramos resumida en su ensayo "Universalidad y Exaltación", publicado en la Hora de España (1937) y que retoma sustancialmente su segunda conferencia en la Casa de la Cultura de Valencia:

Pero lo más importante de Don Quijote no es su pergeño español ni su estructura castellana, sino que dentro de esta estructura castellana se mueve y se agita angustiada una conciencia humana que quiere buscarle salidas al mundo por los caminos del amor y de la justicia (citado por Sánchez 1984: 4, cursiva del autor).

Si bien es cierto esta interpretación antropológica resalta los valores universales del Quijote en cuanto indagación del hombre y de su existencia, lo cual se ajusta con pertinencia a la lectura que ofrece la generación del 98 del texto cervantino a la luz de su profundidad filosófica (Chen 1989: 97-103), el quijotismo, siempre dentro de la concepción unamuniana del término, se explicita también en Rocinante. León Felipe continúa comulgando con lo que escribe en el año 
37; sin embargo encuentra en el ocaso de su vida y después de ser confrontado al exilio y a sus efectos marginalizantes con la tarea de repensar su biografía y el destino que su existencia ha tomado actualmente. Ahora bien, ¿por qué León Felipe escoge a Rocinante como punto de comparación? No es inocente que, en la parte central de su poemario, el poeta se presente como un ser marginal y de menos valor que aquél y que juzgue su trabajo y su situación presente de poeta consagrado a partir de la sabiduría del que se considera un hombre maduro. Esta comparación surge en la sección inicial de Rocinante y su título es altamente significativo "Biografías paralelas". Sus resonancias culturales nos remiten al trabajo más importante que ha proporcionado el escritor helenístico Plutarco a la literatura grecolatina, Vidas Paralelas, en el que se propone dejar constancia de aquellos hombres que se elevaron, mediante sus hazañas e ideales, por encima del resto de los mortales, ya que Plutarco apunta "a la ejemplaridad de estas vidas como suscitadoras de imitación y de emulación" (Cantarella 1972: 224). La motivación del historiador dentro de la obra de Plutarco rebasa, según Cantarella, la simple exaltación de un personaje pues debe mostrársele como modelo de vida (Chen 1997) y el comentarista resume esta concepción de la siguiente forma:

(...) para él la historia constituye sólo la perspectiva, el escenario en el cual los hombres son vistos y a la vez la justificación de su dignidad, de su asunción a una categoría humana superior y casi ideal. Para entrar en ella no basta haber sido creadores de historia (...) sino que el personaje histórico, una vez entrado en la historia puede decirse que se purifica del aspecto contingente de valor paradigmático absoluto (1972: 223-4).

Esto es lo que realiza León Felipe con la figura de Rocinante a quien reivindica con su elogio sacándolo del olvido de la crítica cervantina. Así, el poemario propone la existencia de Rocinante como modelo de vida y de conducta, al cual el hablante lírico espera emular y seguir $\mathrm{y}$, en lo que se refiere a su caso, la captatio benevolentiae funciona con el fin de que, valorando y ponderando la figura de Rocinante, León Felipe se mire a sí mismo y se ponga en paralelo con Rocinante. Es necesario entonces que haya un común denominador que permita la comparación entre ellos y que sirva de presupuesto. Para ello hay que partir de la situación presente del poeta, el cual re-evalúa su carrera y su biografía personal a partir de la sabiduría y de la sensatez de quien se considera un hombre maduro que ha logrado la fama literaria y ha adquirido su renombre en la vejez, en el ocaso de su vida, tal y como ha sucedido también con Rocinante, un jamelgo desdentado que ha saltado también a la gloria literaria como él y que ahora se propone como modelo de su vida.

A la luz de lo anterior, es interesante observar cómo el primer elemento de la comparación es el nombre, con el cual se establece la primera marca de identificación y de identidad y, en palabras de Eugène Nicole, a partir de la nominación "s'affirme la marque du personnage" (1983: 236). Es decir, con la fijación del nombre propio nace el personaje y eso es lo que sucede en el primer poema de la sección "Biografías paralelas". La apelación del hablante lírico a Rocinante se singulariza en una actitud lírica en la que éste se encuentra frente al tú, que la comunicación lírica hace posible captar y expresar, pues “(e)l tú está aquí, generalmente, más cerca del hablante, se hace accesible a la contemplación, se desarrolla en el encuentro (...)" (Kayser 1981: 449). En este sentido, lo que permite en primera instancia este acercamiento es la solidaridad hallada y que se devela, ahora, en la coincidencia de recorridos biográficos: 


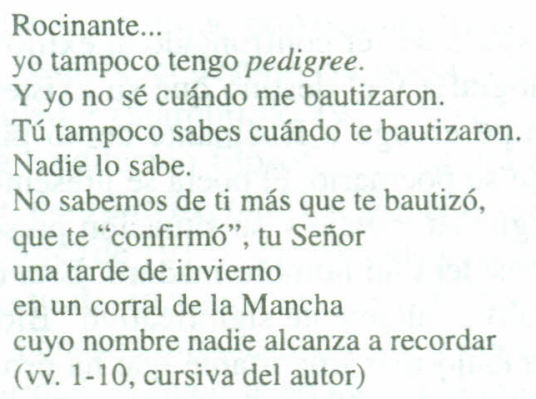

En un acto de anagnórisis, el hablante lírico emerge con una afirmación: la carencia de una genealogía y de un documento que pruebe su linaje (v. 1-2). Recordemos que, con el pedigree, se comprueba el linaje de un animal y la sucesión hereditaria que mantiene el poder de la raíces, parafraseando el sugestivo título del artículo de François Gantheret en el que analiza la relación entre onomástica y fundación de una estirpe (1973: 106). Así, la carencia de la estirpe conduce al desconocimiento del lugar y de la fecha de sendos bautizos (vv. 3-4), el rito fundamental con el que se pone el nombre que designa al sujeto y con el cual es reconocido en el orden social, de manera que tanto el poeta como Rocinante comparten esta ausencia de linaje y la privación de un reconocimiento social que se pierde en la lejanía de una historia poco importante y remota. Por esta razón, se insiste en la salida de esa incertidumbre, de esa oscuridad de la vida, gracias al acto de confirmación al cual son sometidos ambos. Aquí la confirmación se explica en su sentido más prístino, como el acto de ratificación social y de asunción humana del nombre, por lo cual el sujeto se afianza, se transforma en un ser en toda su dimensión alejándose ya de la inseguridad del pasado y apropiándose de un destino con el que se identifica:

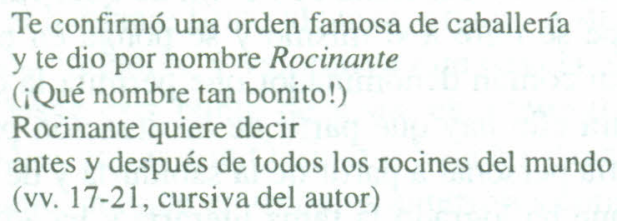

Recordemos que la selección y la comparación con Rocinante no es fortuita; su utilización permite insertar la atribución onomástica dentro del sistema socio-cultural en el que las connotaciones afectan el significado del texto (Nicole 1983: 239). Referirse a Rocinante, un jamelgo sin historia, que entra en la gloria literaria gracias al deseo de don Quijote de hacerse armar caballero (Núñez 1965: 30-4), es ingresar al mundo en el que los ideales de justicia y de virtud interpelan al hombre y, de este modo, lo impulsan hacia grandes empresas, tal y como se ha leído el Quijote bajo el prisma del quijotismo noventayochista (Chen 1989: 104-5) y Rocinante tendrá la función de convertirse en un medio facilitador y un compañero de aventuras de un caballero que busca, como Gregorio Palacín explica en su análisis del acto de armar caballero a don Quijote, "un mundo idealizado y aleccionador" (1971: 3). Con ello, el rocín sale de su anonimato para acompañar a su amo en grandes empresas (Núñez 1965: 26-7); de ahí el doble sentido que adquiere el adjetivo "famosa" relacionado con la orden de caballería, remitiendo al consabido o a la mostración catafórica: célebre e ilustre pues con ello Cervantes otorga la fama a un desconocido rocín; fiel y noble compañero pues don Quijote engrandeció al simple y pobre 
jamelgo. Así, Rocinante sale de la oscuridad que significa la vida simple y rutinaria y se forja un nombre admirado y exaltado por todos; ya León Felipe lo destacaba en el poema inicial de su libro, al relacionarlo con la luz del amanecer, es decir, del nacimiento y de la fama:

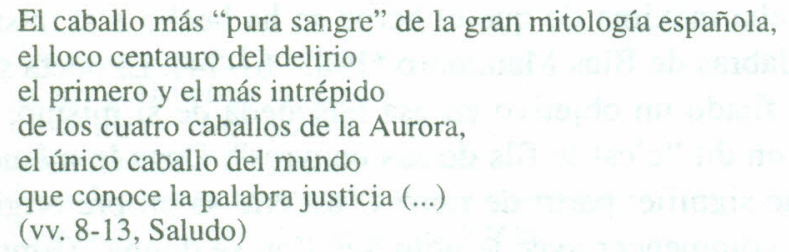

Esie renacimiento, al cual nos referimos, se cristaliza con el nombre que recibe el jamelgo desconocido cuando es re-bautizado por su amo (v. 18), reconociéndole en el nombre una motivación onomástica que describe su destino lumínico como el caballo por antonomasia; tal parece la apelación que se inscribe en la designación del personaje cervantino, que extrae su modelo del código caballeresco y del cual el poema se apropia como verdad autentificando las palabras proféticas de don Quijote: “(...)al fin le vino a llamar Rocinante, nombre, a su parecer, alto, sonoro y significativo de lo que había sido cuando fue rocín, antes de lo que ahora era, que era antes y primero de todos los rocines del mundo" (Cervantes 1979: 21, Cap. 1, Tomo 1, cursiva del autor). Sin embargo, este carácter lumínico se explica también dentro de la concepción del amor que maneja León Felipe, en cuanto la búsqueda de su integración con Rocinante emana de su vocación poética, para quien "(e)l fondo de la inspiración es entonces la consciencia (sic) del amor (...) Es un amor a todos porque está hecho y está haciéndose por todos. El poeta, al tocar, este amor, se vuelve una señal luminosa y así alumbra a la humanidad y le enseña 'la pluma del amor' que lleva" (Rivera 1973: 195).

Ahora bien, dentro de lo que hemos llamado el proceso recapitulativo de una conciencia autobiográfica, es esta "señal luminosa" la que desencadena el poema y el hablante lírico aborda su situación actual a partir de la conciencia de ese proceso que le sirve de punto de discriminación (Starobinski 1974: 67); por eso la imagen del pasado únicamente cobra forma en esta comparación con Rocinante:

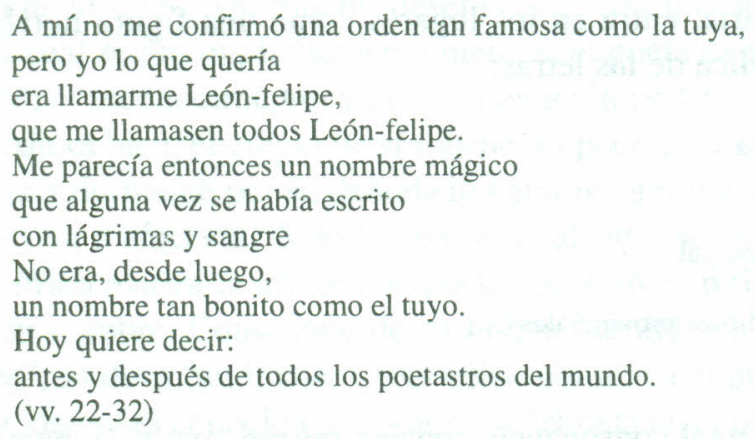

En primer lugar, el hablante lírico no sólo se contenta también en afirmar, dentro de la comparatio a la que asistimos, el cambio consciente de nombre al cual aspira, sino también el hecho de que, como Rocinante, ha dejado un pasado incierto y se ha forjado un nuevo nombre. 
Por ello, en segundo, el poeta desea mostrar que su entrada al mundo de las letras y su consiguiente fama se la debe a sí mismo, pues al igual que Rocinante, la carencia de las raíces y de un pasado es sinómimo del esfuerzo y la convicción de forjarse un nombre y, en este caso, de forjarse un destino. Por eso, el cambio consciente de una identidad gracias al nombre representa desde un punto de vista mítico, la prueba máxima de que el héroe se ha hecho a sí mismo, de que es un héroe sin padre según las palabras de Blas Matamoro (1983: 61-74). El poeta se debe a lo que es y no a sus orígenes, se ha fijado un objetivo en esa búsqueda de sí mismo: "D'un homme qui 'part de rien', s'il réussit, on dit “c'est le fils de ses oeuvres". Dans le même sens, on dit qu' "il se fait un nom". Mais que signifie: partir de rien? C'est être sa propre origine. Se nommer soi-même, c'est naître de soi, commencer avec le nom que l'on se donne" (Emmanuel 1983: 86). Este nacimiento se perfila claramente con la asunción de un nuevo nombre, que anuncia su aspiración a forjarse un destino célebre y famoso, pues "se llama León, como doce Papas. Y Felipe. Como cinco reyes" (Cipriano Rivas Cherif, citado por Elorriaga 1969: 96). De manera que con este nombre, León-felipe, es desde ahora confirmado en el mundo de la poesía, marcando el nuevo nacimiento que se ha operado en cuanto sujeto que es capaz de romper la distancia entre el hombre que fue y el que es ahora; se trata de un acto lumínico en el que Leónfelipe neutraliza tal divergencia en un solo hombre, integrado así a partir de un punto de vista estético y creativo (Bajtin 1982: 133) y que destaca, en ese espacio iniciático, la distancia interior recorrida ante el progreso y el conocimiento adquiridos (Suleiman 1979: 24 y 30), por el cual el hablante lírico ha pagado el precio de su dedicación "con lágrimas y sangre" (v. 28) para ganarse su lugar entre "todos los poetastros del mundo" (v. 32).

Con este nombre, el hablante lírico accede a una nueva existencia, que se diferencia de la anterior por sus connotaciones un poco negativas y se caracteriza por el éxito obtenido con su carrera como poeta, razón por la cual ya ni recuerda su antiguo nombre ("Mi nombre anterior nadie lo recuerda. / Ni yo siquiera lo recuerdo", vv. 36-7). Nombrándose de esta manera y olvidándose de su pasado, el poeta asume el riesgo de su destino (Emmanuel 1983: 86) y, al mismo tiempo, reivindica que su identidad como sujeto está íntimamente ligada a su producción poética. Decíamos que era un riesgo pues, desde este momento, su nuevo nombre usurpa el lugar de un recuerdo remoto y de una existencia anónima y se hace inseparable de su persona. En este sentido, el protagonista que se bosqueja a lo largo del poema es un hombre que ha logrado la notoriedad dentro de la institución literaria, entra en los lugares como una figura notable y se codea con las personalidades de la república de las letras:

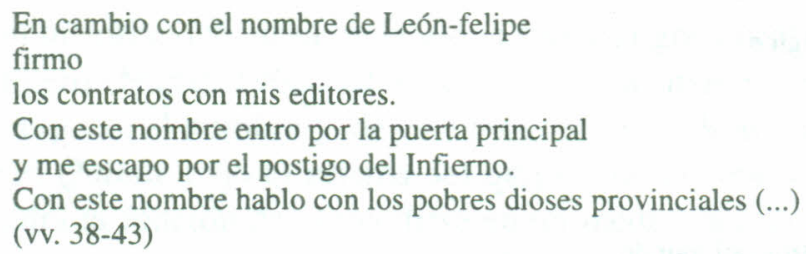

Bajo tales atributos, el sujeto, en total consonancia consigo mismo, exulta su nueva identidad fundiéndose en una euforia que le permite extender su radio de acción hacia el mundo y hacia la humanidad toda entera y el poema se transforma en la manifestación de este flujo recíproco (Kayser 1981: 446) en el que el poeta se solidariza con los hombres sufrientes (Paulino 1982: 41) 
y con aquellos para quienes el imperativo es resolver el enigma de la existencia. Determinado por el signo de la hermandad por el cual el poeta se aleja de cualquier arrebato de ensimismamiento y de egoísmo, León-felipe, como se hace llamar así con guión y minúscula, proclama el compromiso de compartir, al mismo tiempo, con los hombres y también con sus pares en materia de poesía:

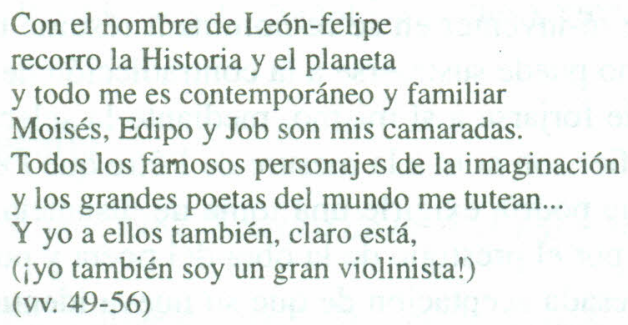

Gracias a la adquisición del nombre, el poeta emprende ese viaje que lo obliga a transitar todo el orbe (v. 50) y a codearse con todo tipo de gentes; pero para ello, para tener éxito, ha descubierto que comparte con los hombres su condición de mortales, reflejado en la enumeración "Moisés, Edipo y Job", ya que como ellos también busca su camino y su destino, y, principalmente, paga el precio del sufrimiento. Sin embargo, también este nombre le abre el acceso ya sea a las fuentes insondables de la creación poética (v. 53), ya sea al reconocimiento del círculo de los poetas (v. 54). De este modo, el poeta recoge los frutos de su trabajo transformado ahora en un bien-posesión que puede legar como obra para "el mundo entero" (v. 58), en la medida en que la palabra poética moldea el cosmos y éste es aprehendido por la necesidad del poeta de compenetrarse con las cosas gracias al amor intellectualis:

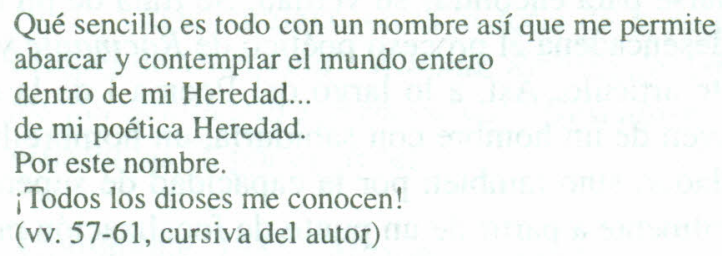

Por lo tanto, sin mucho desenfado y con una gran conciencia de la posición que hoy ocupa, la cual según implícitamente merece, el poeta explora los alcances de lo que muy bien se ha ganado, el reconocimiento y la consideración (v. 61).

Ahora bien, el elogio de sí mismo no podría ser ostentoso en un poema que hemos caracterizado anteriormente por su denodado valor recapitulativo; en ningún momento hay una mostración excesiva o afectada. Todo lo contrario, al situarse en su circunstancial proceso evaluativo, el hablante lírico matiza la imagen de poeta "de marca" refiriéndose de manera directa a la adquisición de su nombre. Consciente de su origen humilde en tanto hombre sin pasado que no posee "pedigree", es decir, un linaje, León-felipe minimiza el punto de llegada de su recorrido biográfico con la identidad conocida por todos y celebrada en el orbe mofándose de su endiosamiento:

$\mathrm{Y}$ en realidad León-felipe

no es más que un mote,

un apodo,

un remoquete, 


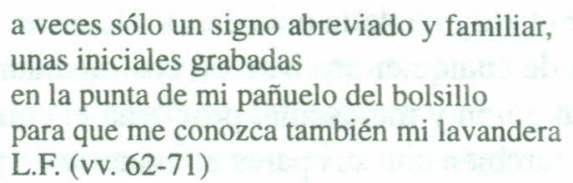

Como Dominique Desanti afirma, "(s)e ré-inventer en se re-nommant résume tous ces désirs contradictoires” (1983: 91); así, el poeta no puede sustraerse a la contradicción de marcar la entereza con la que ha asumido la empresa de forjarse a sí mismo, mediante la selección de un pseudónimo que cumple la función "d'amplifier son nom à la mesure de l'être que l'écrivain sent en soi" (Desanti 1983: 93) y el rechazo que podría exigirle una toma de distancia. Desde nuestro punto de vista, esta distancia se impone por el prestigio de la obra del poeta y por su renombre y se manifesta, en el poema, en la confesada aceptación de que su nueva identidad corresponde a una máscara, es decir, a un nombre seleccionado voluntariamente. Aquí el uso de "mote", de "apodo" o de "remoquete" es altamente significativo, pues la redundancia del término instaura una mitigada desvalorización del sujeto con el fin de presentarse en su condición de hombre y no de dios. De esta manera, alejándose de la posición de privilegio y de autoridad, merecidamente ganada y materializada en el pseudónimo que resume su éxito y con el cual firma contratos y mantiene la expectación del mundo literario, el poeta se desnuda intentando reconciliar sus orígenes modestos y su nueva identidad con el recordatorio de que el nombre adoptado, León-felipe, se desvanece y se transforma en unas simples iniciales (vv. 67-8) que sirven para identificar algo tan íntimo y personal como sus pañuelos (v. 70).

En conclusión, dentro de esa preocupación de sí mismo señalada por Michel Foucault como fundamento de las prácticas autobiográficas en el mundo grecolatino (1991: 50-72), el sujeto está obligado a repensarse y a escucharse para encontrar su verdad. Se trata de un examen de conciencia (Foucault 1991: 73-4) que desencadena el proceso poético de Rocinante y, en especial, del primer poema analizado en este artículo. Así, a lo largo del Poema I de la sección "Biografías paralelas", se bosqueja la imagen de un hombre con sabiduría, un hombre liberado no solo por el poder del proceso recapitulador, sino también por la capacidad de superar la linealidad del tiempo y contemplarse integralmente a partir de un punto de focalización presente: la de un León Felipe que interpreta su destino en relación con su punto de llegada, el poeta conocido por todos:

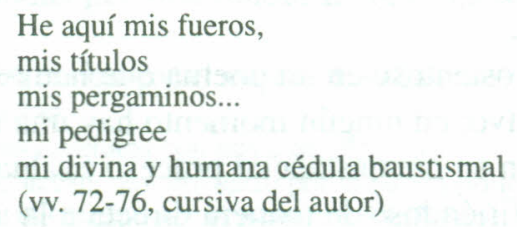

El poema se convierte, entonces, en mostración de la lucha que inspira al sujeto a imponerse y a definirse en su carrera como poeta. Es una conquista que aparece en toda su dimensión con la reivindicación final, pues el hablante lírico insiste en el derecho a regocijarse y a exhibir su historia personal: el éxito no se lo debe a nadie y él mismo se ha forjado el nombre. Por eso, el texto termina con la superación de la carencia y la incertidumbre iniciales, por cuanto el poeta marca, de una vez por todas, su pertenencia y su valía personal. Francisco María Núñez, 
un comentarista costarricense que ha hecho una probanza de Rocinante y del rucio, encuentra que los dos animales están en total consonancia con sendos amos (1965: 27); esto es lo que sucede también entre Rocinante y León Felipe, quienes se hermanan en pensamiento y en corazón para demostrar que cada uno puede forjarse su destino y escribir una misma y gran historia: la de los seres que saben afrontar las luchas y embates y asumir sus ideales.

\section{Bibliografía}

Bajtín, Mijail. 1982. Estética de la creación verbal. México D.F.: Siglo Veintiuno Editores.

Cantarella, Raffaele. 1972. La literatura griega a la época helenística e imperial. Buenos Aires: Editorial Losada.

Cervantes, Miguel de. 1979. El ingenioso hidalgo don Quijote de la Mancha. Madrid: EspasaCalpe, 28a. edición.

Chen Sham, Jorge.1989."El Quijote y su lectura: el discurso de la crítica costarricense (19401986)". Imprévue. 1: 89-128.

1991. "Profundidad y dualismo: el doble protocolo de lectura en Meditaciones de Quijote". Revista de Filología y Lingüística. 18 (1): 7-18.

1997.'Vidas paralelas en la historia de la recepción cervantina: Gregorio de Mayáns y Miguel de Unamuno". Káñina, Revista de Artes y Letras (Número extraordinario, Actas del Seminario Internacional "Descubrir y repensar a nuevos valores en las letras hispánicas"), por aparecer.

Desanti, Dominique. 1983. “Masquer son nom”. Corps écrit (Le Nom). 8: 91-98.

Elorriaga, José A. 1969. “León Felipe (1884-1969)”. Revista Hispánica Moderna. 35 (1-2): 96102.

Emmanuel, Pierre. 1983. "Changer de nom”. Corps écrit (Le Nom). 8: 85-89.

Foucault, Michel. 1991. Tecnologías del yo y otros textos afines. Barcelona: Ediciones Paidós Ibérica.

Gantheret, François. 1973. "Le pouvoir des racines". Nouvelle Revue de Psychoanalyse. 8: 95113.

Kayser, Wolfgang. 1981. Interpretación y análisis de la obra literaria. Madrid: Editorial Gredos, 5a. reimpresión. 
León Felipe. 1982. Ganarás la luz. Madrid: Editorial Cátedra (edición a cargo de José Paulino). 1982. Rocinante. Madrid: Editorial Visor.

Matamoro, Blas. 1983. "El héroe sin padre". Cuadernos Hispanoamericanos. 401: 61-75.

Nicole, Eugène. 1983. "L'onomastique littéraire". Poétique. 54: 233-53.

Núñez, Francisco Ma. 1965. Rocinante y Rucio (Ensayo). San José: Imprenta Lehman.

Ortega y Gasset, José. 1990. Meditaciones del Quijote. Madrid: Editorial Cátedra, 2a. edición (a cargo de Julián Marías).

Palacín, Gregorio B. 1971. "Sobre el acto de armar caballero a don Quijote”. Hispanófila. 42: 1-6.

Rivera, Tomás. 1973. "La teoría poética de León Felipe”. Cuadernos Americanos. 186 (1): 193214.

Sánchez, Alberto. 1984. "Los ensayos cervantinos de León Felipe”. Insula. 452-453: 4.

Suleiman, Susan. 1979. "La structure d'aprentissage: Bildungsroman et roman à thèse". Poétique. 37: 24-42.

Starobinski, Jean. 1974. La relación crítica (Psicoanálisis y Literatura). Madrid: Taurus Ediciones.

Unamuno, Miguel de. 1966. Obras Completas. Madrid: Editorial Escelicer, tomo I. 